\title{
EFFECT OF CHICKEN BONE ASH ON MECHANICAL PROPERTIES OF Al 8011 REINFORCED WITH SILICON CARBIDE
}

DOI:10.36909/jer.ICMMM.12347

\author{
NITHYANANDHAN.T* RAMAMOORTHI.R ${ }^{* *}$ \\ *Asst.Professor, Sri Krishna College of Technology, Coimbatore \\ ${ }^{* *}$ Professor, Sri Krishna College of Engineering \&Technology, Coimbatore \\ *Corresponding Author: anandhan8.mech@gmail.com
}

\begin{abstract}
To deal with demands in advanced engineering applications that focus on improved mechanical properties of metal composites, aluminium metal matrix composites are recommended. This paper deals with mechanical characteristics of aluminium (A18011) fortified with silicon carbide ( $\mathrm{SiC}$ ) and Chicken Bone Ash (CBA). Varying percentages of silicon carbide starting from $0 \%, 2 \%, 4 \%, 6 \%, 8 \%$ and $10 \%$ with percentages of chicken bone ash starting from $10 \%, 8 \%, 6 \%, 4 \%, 2 \%$ and $0 \%$ respectively for the purpose of testing and reinforcement. Stir casting method is employed to manufacture the components. In this paper, fatigue test, impact test and hardness test is carried out to obtain results about the mechanical characteristics of the components. The mechanical characteristics observed in the resultant composites as per ASTM standards and microstructural study is used to characterize the distribution of reinforcements. Ultimately as the weight percentage of reinforcement materials increases, elevation in mechanical characteristics of material is discerned.
\end{abstract}

Keyword: A18011, SiC, Chicken Bone Ash, Hardness test, Fatigue test \& Impact test . 


\section{INTRODUCTION}

Metal Matrix Composites are the materials with improved mechanical characteristics which are made of coalescence of two or more materials. This paper covers the hybrid composite with the Al8011 as the framework matrix metal and chicken bone ash (CBA) along with silicon carbide

(SiC) as fortification agents. The impacts of stir welding specification were inspected by mechanical studies and microstructural analysis portrayals. The composites microstructure and scattering of molecule fortifications were investigated via an optical microscope and furthermore the mechanical characteristics of yield quality, extreme quality and stretching were broken down utilizing all inclusive testing machines (B.SURESHBABU, 2018). Studies performed with assessment of aluminum mix LM6 with expanded weight extent of silicon carbide and aluminum oxide and set up that increase in weight division achieved increase in the Rockwell hardness number. The fortification of fly debris along with Al6061 brought about an expansion in hardness all through on account of the hard fly debris particles (SINGH D, SINGH H et al., 2012). Metal structure composites uncover another period of designing stuff which join metallic attributes of framework amalgams with the properties of fortifications, that is required for the creation adventures as of now. Amid different particulate fortifications like Silicon Carbide, aluminium oxide, boron carbide, Spasm, Aluminum nitride, fly debris and so forth, fly debris presents as a characteristic source, minimal effort, noxious modern waste particulate support(K. KAVIYARASAN, 2018). Diverse weight parts of fortification were utilized to manufacture the composites. Checking electron magnifying instruments furnished with vitality dispersive X Ray analyzer is utilized for small scale basic portrayal. The investigations were done in characteristics like thickness, hardness, and extreme rigidity (D. SIVA PRASAD, 2011). This investigation bases on the mechanical attributes of Al6061 strengthened with coconut shell garbage and boron carbide granules are casted utilizing mechanical mixing measure. In this test, supporting boron carbide has different elevations of 5, $8 \& 3 \mathrm{wt} \%$ and another coconut shell trash 
has 1, 1 and $2 \mathrm{wt} \%$ for all models. The result assumes that the inflexibility and break sturdiness would rise in stronghold substance stood out from unadulterated aluminum composite. (T.NITHYANANDHAN, 2017). The paper deals with the production of aluminum based combination metal grid composite and subsequently depicts their of blend anticipating has been

used in the current assessment to convey aluminum (6063) compound fortified with Silicon carbide (Sic). Here Aluminum (6063) combination is used as a base metal and Silicon carbide (SIC) is used as are in compelled material with the mutt rein for concrete as Rice husk garbage (HARIDASS.R, 2018).

\section{MATERIAL SELECTION}

1. ALUMINIUM 8011

2. SILICON CARBIDE (SiC)

3. CHICKEN BONE ASH (CBA)

\section{ALUMINIUM 8011}

Al 8011 is an amalgam with iron and silicon metals is appeared in fig 1. The standard controlling and its piece are kept up by the Aluminum Association. The great mechanical properties of aluminum empower heat treatable and weldability. Aluminum 8011 is utilized in car businesses, hardware, day by day supplies, building exchanges, bundling and so on

It has a decent surface consummation material, high erosion obstruction generally appropriate for welding. It additionally shows high wettability. Most customarily open as h14, h16, h24 and h26 sheets of which h14 has more structure capacity. Aluminum 8011 has a thickness of $2.71 \mathrm{~g} / \mathrm{cm}^{3}$. Table 1 shows the synthetic creation of Aluminum 8011. 


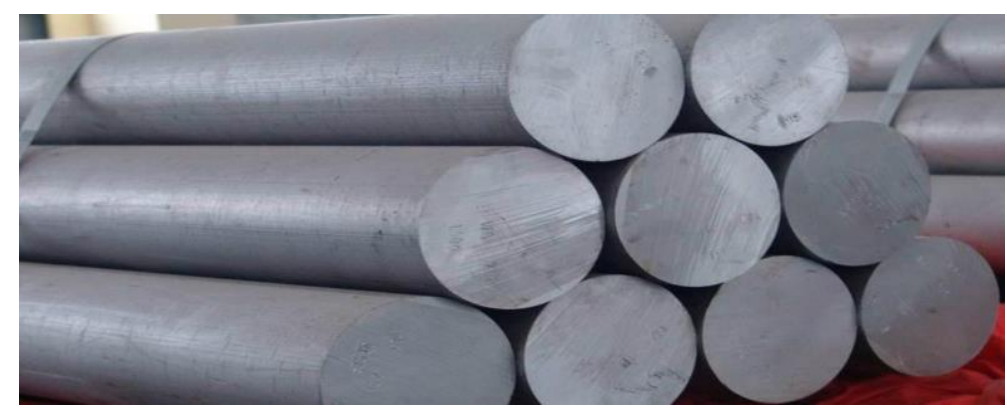

Fig1. Al8011

Table1. Compound creation for aluminum combination 8011

\begin{tabular}{|c|c|}
\hline ELEMENTS & WEIGHT\% \\
\hline Aluminium(Al) & $97.5 \sim 99.1 \%$ \\
\hline Iron(Fe) & $0.6 \sim 1.0 \%$ \\
\hline Silicon(Si) & $0.5 \sim 0.9 \%$ \\
\hline Copper(Cu) & $0 \sim 0.1 \%$ \\
\hline Manganese $(\mathrm{Mn})$ & $0 \sim 0.1 \%$ \\
\hline Magnesium(Mg) & $0 \sim 0.1 \%$ \\
\hline Zinc $(\mathrm{Zn})$ & $0 \sim 0.1 \%$ \\
\hline Chromium(Cr) & $0 \sim 0.1 \%$ \\
\hline Titanium(Ti) & $0 \sim 0.05 \%$ \\
\hline Residuals & $0 \sim 0.15 \%$ \\
\hline
\end{tabular}

\section{SILICON CARBIDE}

Silicon carbide ( $\mathrm{SiC}$ ) otherwise called carborundum, is a compound of silicon and carbon with substance equation $\mathrm{SiC}$ is appeared in Fig 2. Moissanite an incredibly uncommon mineral is the wellspring of silicon carbide. It is utilized in different applications as cutting apparatuses, vehicle parts, pyrometry and so forth $\mathrm{SiC}$ is used in semiconductor devices that work at high temperatures or high voltages. Muffle furnace is used in this process to preheat silicon carbide 
and then added to the molten metal. As indicated by current studies, Silicon carbide 88 and $90 \%$, annex amounts of $2.5 \%$ are the most customary grades of Silicon Carbide. Since the liquefying extremity of silicon carbide is about $2700^{\circ} \mathrm{C}$, this makes the liquefying cycle longer, we have to include it before different composites and added substances, as a rule it is included at complete casting system's $33 \%$ chance to half time, in order to let it possess enough energy for softening and response. Taking all things together, silicon carbide metallurgy can supplant ferrosilicon and Increment the quantity of graphite, and upgrade mechanical properties of the projecting.

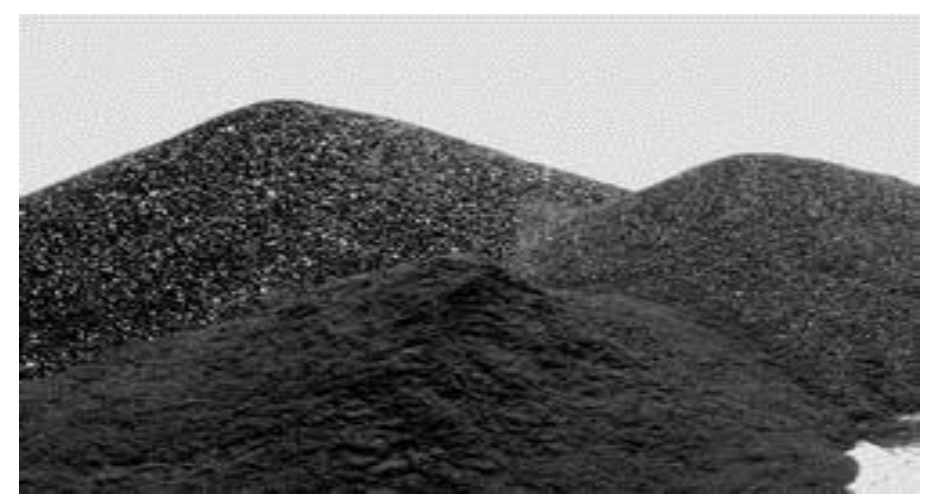

Fig 2. SILICON CARBIDE

\section{CHICKEN BONE ASH}

Chicken ash bone is the combustion product of chicken bone is shown in Fig 3. Studies show that it's an excellent metal biosorbent for certain metals. Bone ash is often used in the cupellation process in metallurgy. Bone ash in a metal matrix improves stiffness, hardness, strain and energy absorbing properties. Chicken bone ash mainly consists of calcium hydroxyapatite or calcium phosphate. Its properties enable it to make the metal surface more smooth and increases stiffness of the metal matrix structure. Addition of Chicken Bone Ash to coarse materials, for instance, feldspars, can lower the liquids temperature and consequently advance fluid stage sintering. 


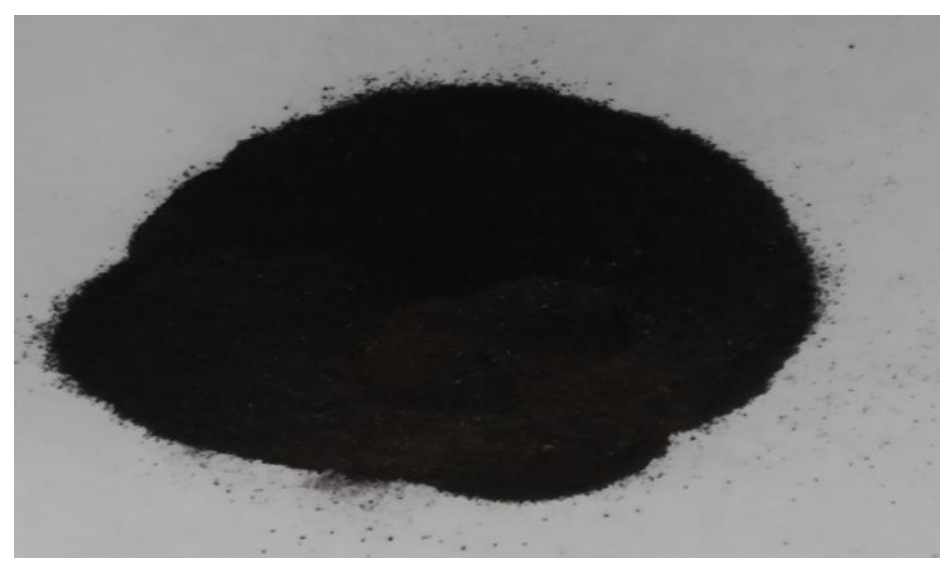

Fig 3. CHICKEN BONE ASH

\section{STIR CASTING PROCESS IN HYBRID MATERIALS PRODUCTION}

The most efficient, productive method of production of metal matrix composites is Stir casting method. This method produces metal composites with uniformly distributed reinforcement's particles within the metal matrix structure. In this method, an induction furnace is used to melt the metal in the metal crucible. The melting temperature of the stir casting ranges from $650^{\circ} \mathrm{C}$ to $850^{\circ} \mathrm{C}$. The reinforcements should be preheated before adding to the molten metal. Usually preheating is done in a muffle at a temperature of $350^{\circ} \mathrm{C}$. The specification of the furnace was shown in table 2. Mild steel blades rotate at a constant speed of $400 \mathrm{rpm}$ at $700^{\circ} \mathrm{C}$ at 30 mins for each test component specimen. Its focal points lie in its straightforwardness, adaptability and materialness to huge amount production with cost advantage. The serious issue of this cycle is to get adequate wetting of molecules by fluid metal and to get a homogenous scattering of the particulates. Stir Casting method includes blending of liquefy, in which the dissolve is mixed constantly which uncovered the softened surface to the environment which watches out for persistent oxidation of aluminum dissolve. Because of consistent oxidation, the wettability of the aluminum lessens and the support particles stay unmixed. The stir casting setup was shown in Fig 4. The different weight percentage of the composition was mentioned in the table3.The Samples of the composition was shown in Fig 5. 


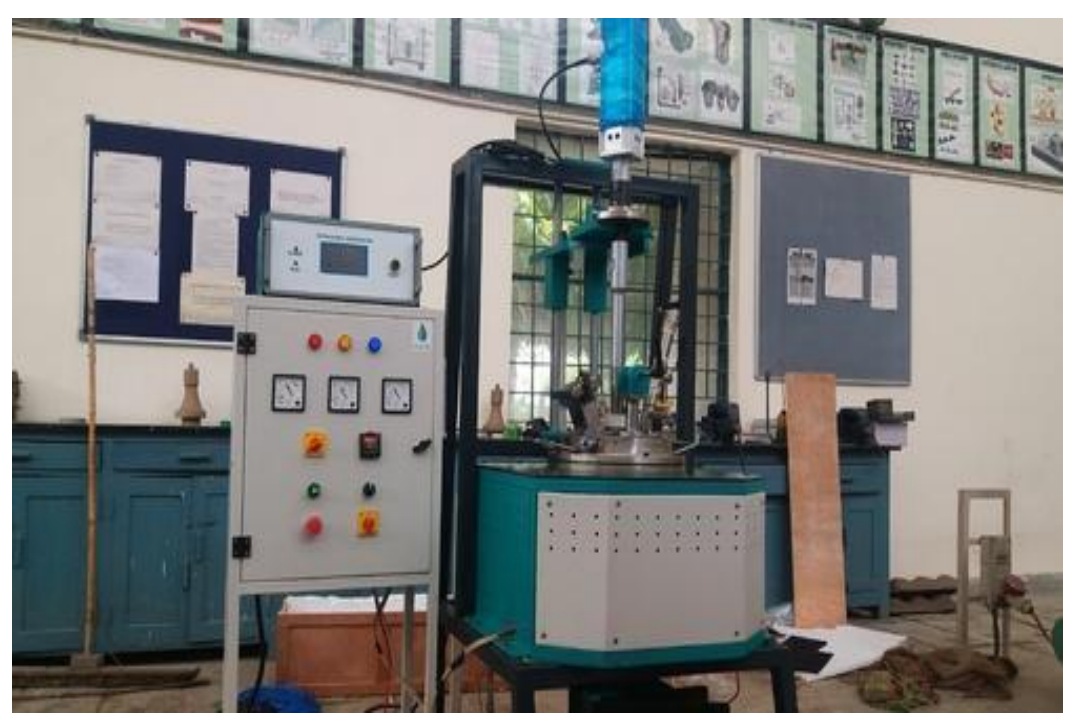

Fig 4. STIR CASTING SETUP

Table 2. FURNACE SPECIFICATION

\begin{tabular}{|cc|}
\hline Capacity & $\mathbf{2} \mathbf{~ k g}$ \\
\hline Operating Temperature & $100-1200^{\circ} \mathrm{C}$ \\
\hline Operating Voltage & $440 \mathrm{~V}$ \\
\hline Phase & 3 Phase \\
\hline
\end{tabular}

Table 3. COMPOSITION PERCENTAGE

\begin{tabular}{|c|c|c|c|}
\hline $\begin{array}{c}\text { SPECIMEN. } \\
\text { NO. }\end{array}$ & $\begin{array}{c}\text { AL 8011 IN } \\
\text { WT\% }\end{array}$ & $\begin{array}{c}\text { SILICON CARBIDE } \\
\text { IN WT\% }\end{array}$ & $\begin{array}{c}\text { CHICKEN BONE ASH IN } \\
\text { WT\% }\end{array}$ \\
\hline 1 & 100 & 0 & 0 \\
\hline 2 & 88 & 10 & 4 \\
\hline 3 & 88 & 8 & 6 \\
\hline 4 & 88 & 6 & 8 \\
\hline 5 & 88 & 4 & 10 \\
\hline 6 & 88 & 2 & \\
\hline
\end{tabular}




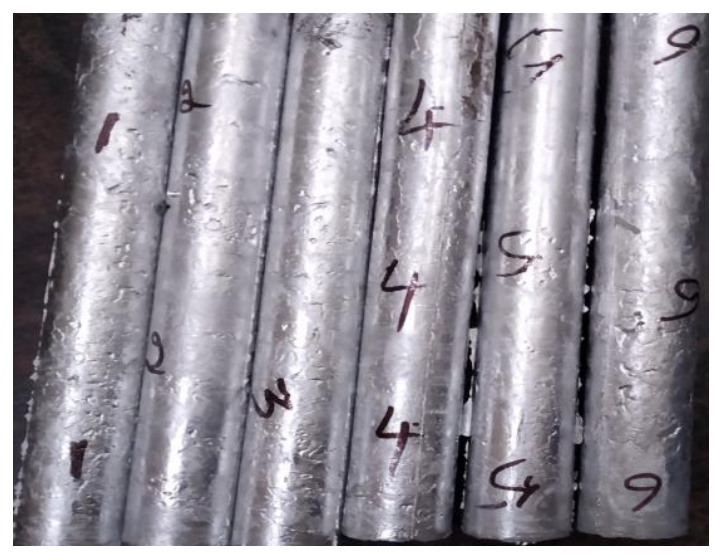

Fig 5. Samples of the composites

\section{TESTING, RESULT AND DISCUSSION}

\section{FATIGUE TEST}

The strategy recorded in ASTM 606 was continued as per ISO 1143 and BS 3518 part2 for pivoting bowing weariness tests. The impact of fluctuating pressure is ordinarily met in cyclic stacking of material. The perpetual basic change prompting breaks because of outside strains and stresses is considered as the boundary of this test. The example surface is cleaned as smooth as could be expected under the circumstances and deformities on surface and profound scratch/machining marks were watched. The test is done in room temperature. According to the necessities six examples were readied and the results are given in Table 4 .

Table 4. Fatigue strength of Compositions

\begin{tabular}{|c|c|c|c|c|c|c|}
\hline Specimen & 1 & 2 & 3 & 4 & 5 & 6 \\
\hline $\begin{array}{c}\text { Fatigue Strength } \\
\text { (MPA) }\end{array}$ & 119 & 126 & 130 & 132 & 135 & 139 \\
\hline
\end{tabular}

During the experiment substantial change in fatigue strength of the six specimens was observed and shown in Fig 6. 


\section{Fatigue Strength}

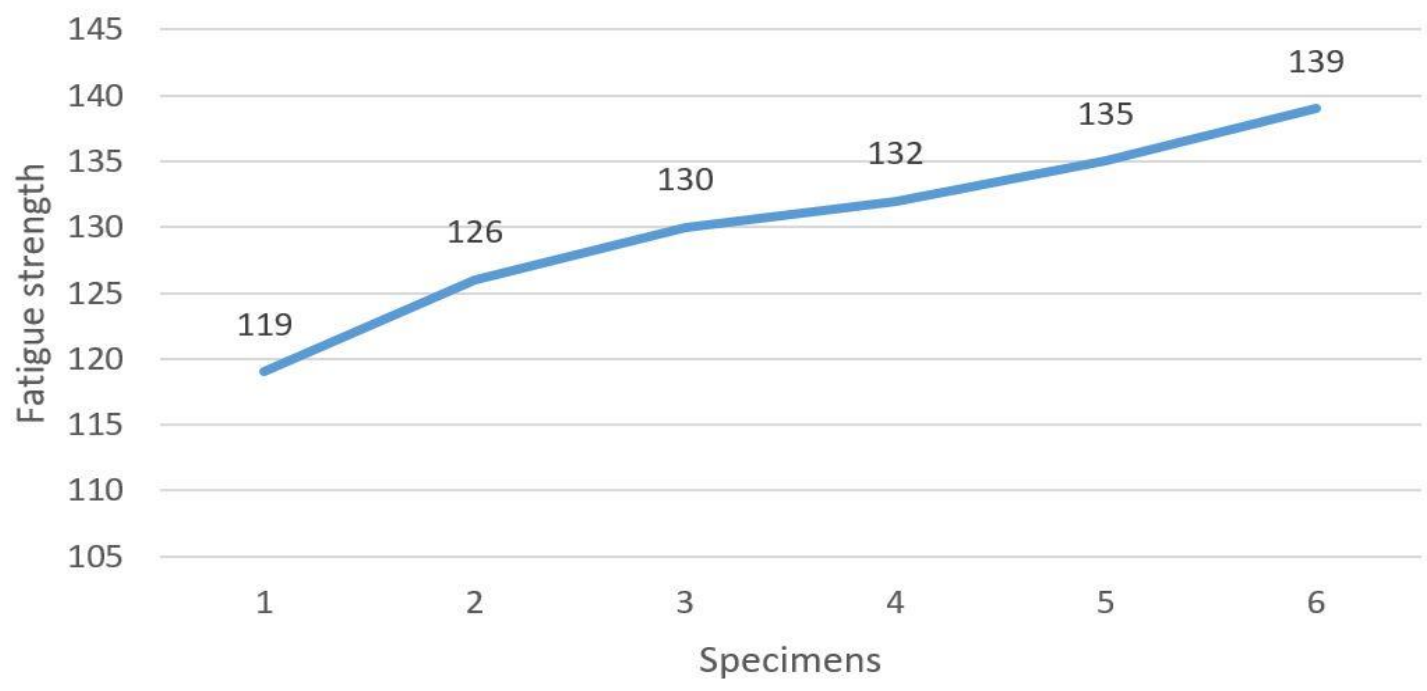

Fig 6. Fatigue strength of six specimens

\section{IMPACT TEST}

The procedure listed within the ASTM E23-18 was followed and specimen rods of length 55mm and width $10 \mathrm{~mm}$ were made. The impact test is used to make conclusions about the toughness of materials. Impact testing machines assess an item's ability to withstand high-rate stacking and it is usually used to decide the administration life of a section or material. Effect obstruction can be among the most moving characteristics to quantify. When a force is applied in a material until it reaches its fracture point, a part of energy is absorbed and it is used as a parameter in the impact test. From the obtained values, important conclusions like ductility or brittle nature of the material can be derived. Six specimens of proposed dimensions are made and prepared for impact test and the results obtained in Table 5.

Table 5. Impact strength of the Composition

\begin{tabular}{|l|c|c|c|c|c|c|}
\hline & \multicolumn{6}{|c|}{ Observed Values } \\
\hline Specimens & 1 & 2 & 3 & 4 & 5 & 6 \\
\hline $\begin{array}{l}\text { Energy } \\
\text { Absorbed } \\
\text { in joules }\end{array}$ & 10 & 12 & 13 & 16 & 17 & 21 \\
\hline
\end{tabular}


The test evaluates the Indent strength of material under shock loading was noted in Fig 7.

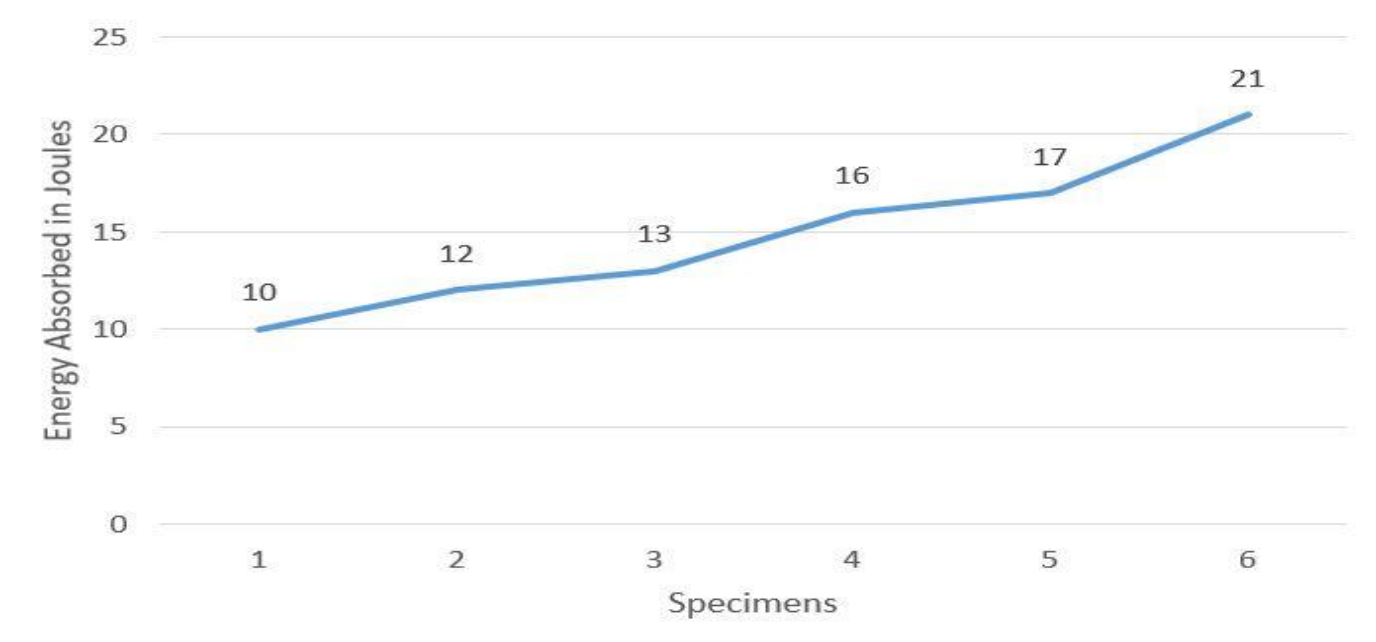

Fig 7. Indent strength of material under stun stacking of three Specimens

The energy needed to break the example is gotten straightforwardly from the test. Examples appeared in fig 7 were shifted scope of effect quality because of contrast in their piece.

\section{HARDNESS TEST}

In general obstruction to penetration is known as hardness. Hardness values directly vary with the obstruction provided against penetration. Microstructure, strain hardening, grain size etc. affects the hardness values of a material. In order to proceed with the test procedure listed as ASTM E18-7, six rods of $25 \mathrm{~mm}$ length and $30 \mathrm{~mm}$ diameter are made from different combinations of SiC and CBA as reinforcements with A18011. Tests are done on every one of the six examples. An extensive change in the hardness of the six examples was seen during the examination. Six examples of proposed measurements are had and arranged for effect test and the outcomes got in Table 6. Examples appeared in fig 8 were fluctuated scope of Hardness because of distinction in their organization. 


\section{Table 6. Hardness of six specimens}

\begin{tabular}{|c|c|c|c|c|c|c|}
\hline & \multicolumn{7}{|c|}{ Observed Values } \\
\hline Test Parameter & 1 & 2 & 3 & 4 & 5 & 6 \\
\hline $\begin{array}{c}\text { Hardness values } \\
(\text { HBN) }\end{array}$ & 90 & 92 & 96 & 101 & 110 & 120 \\
\hline
\end{tabular}

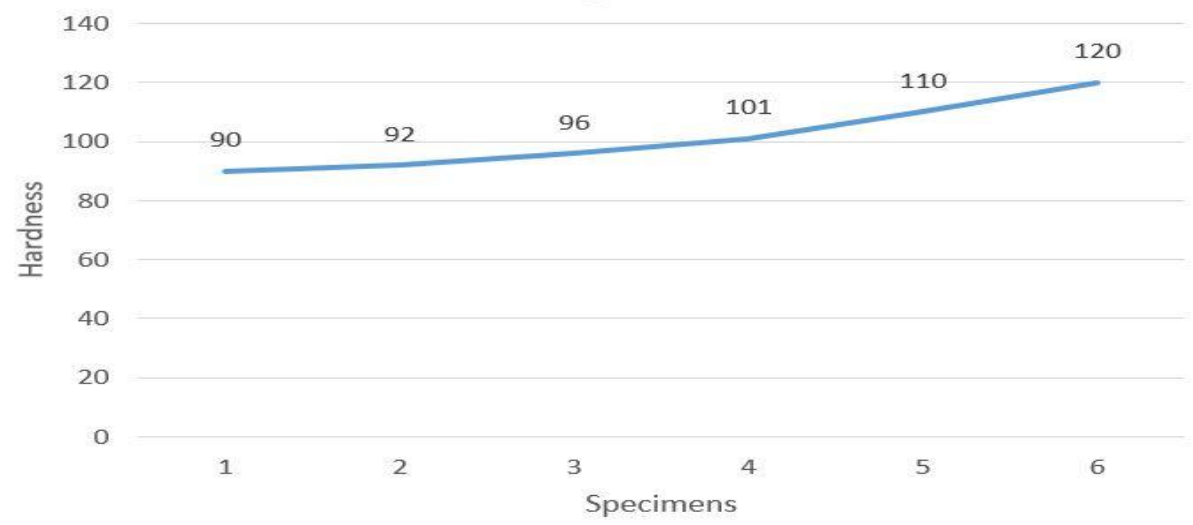

Fig 8. Hardness of six specimens

\section{MICROSTRUCTURE TEST}

Assessment of the microstructure of a material furnishess data used to decide whether the basic boundaries are inside precise particulars. The investigation results are utilized as a basis for approval or rejection. The technique recorded inside the standards ASTM E766 was followed. For metallographic assessment tests were readied. This final cleaning stage likewise served to engrave Keller's reagent Molecule size, dispersion, and shape were examined by picture examination methods.

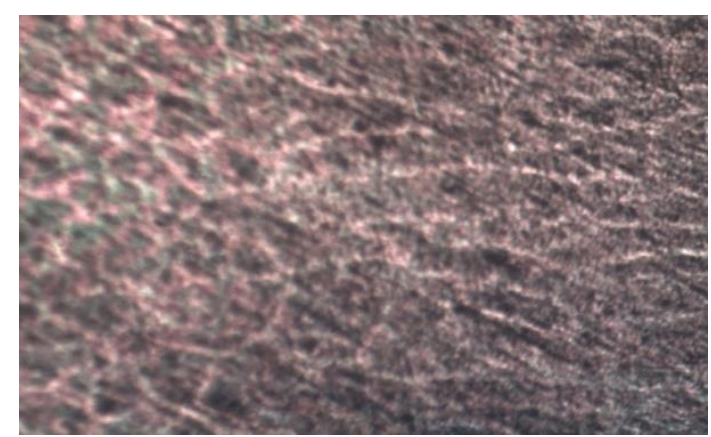

a. $\mathbf{A l}+0 \% \mathrm{SiC}+0 \% \mathrm{CBA}$ 


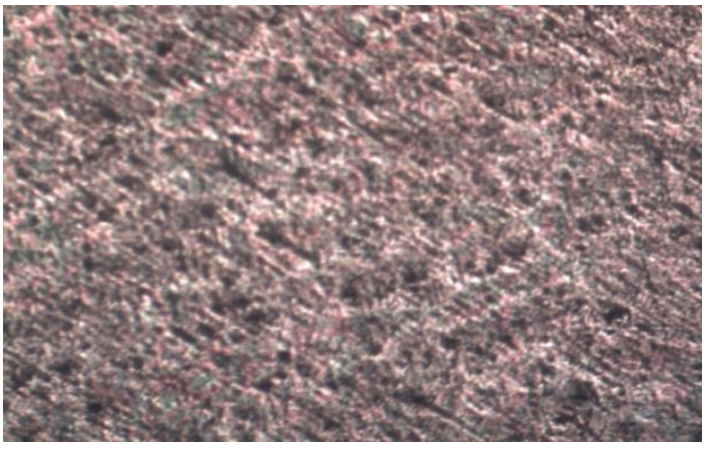

b. $\mathrm{Al}+\mathbf{1 0} \% \mathrm{SiC}+\mathbf{2 \%} \mathrm{CBA}$

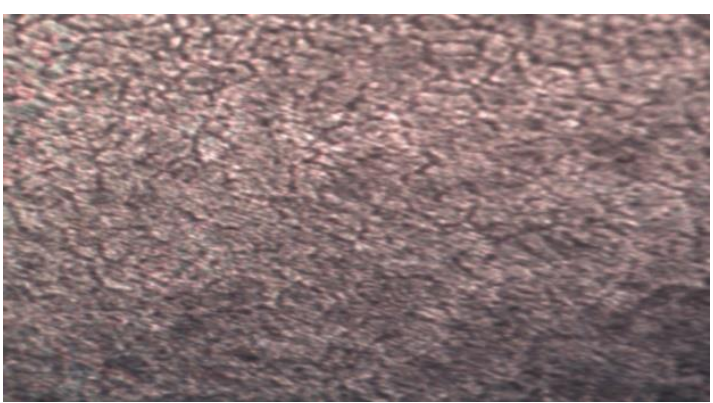

c. $\mathrm{Al}+8 \% \mathrm{Sic}+4 \% \mathrm{CBA}$

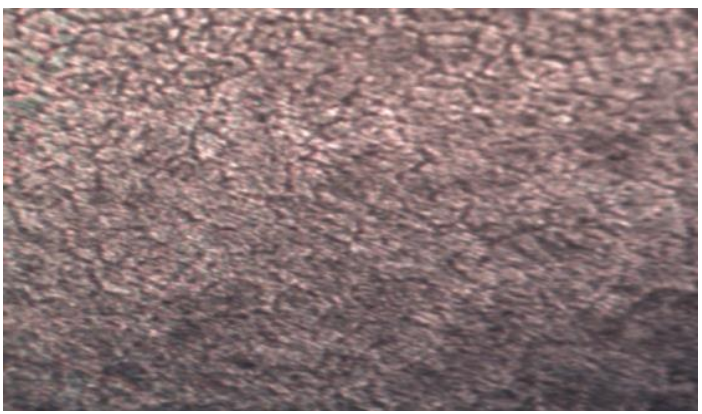

d. $\mathrm{Al}+6 \% \mathrm{SiC}+6 \% \mathrm{CBA}$

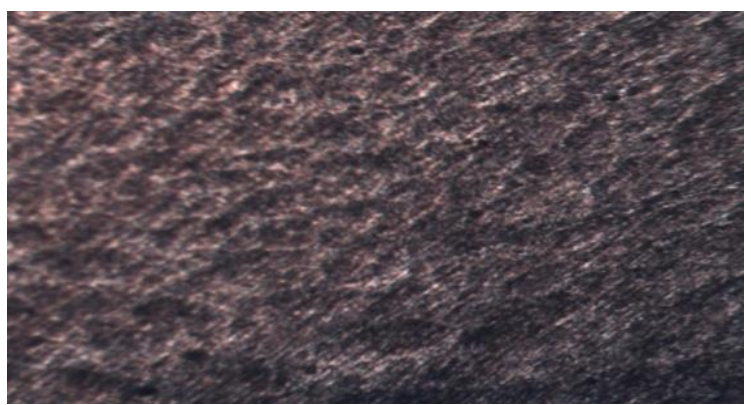

e. $\mathrm{Al}+4 \% \mathrm{Sic}+8 \% \mathrm{CBA}$

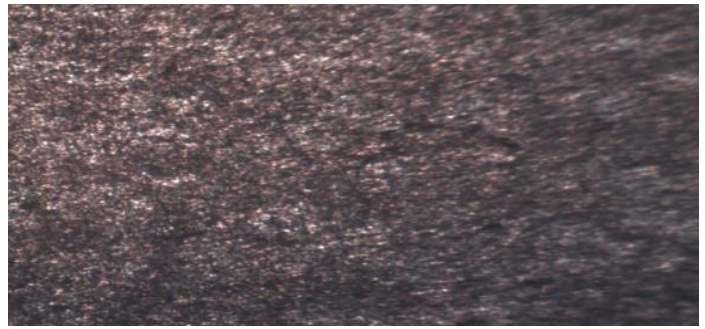

f. $\mathrm{Al}+\mathbf{2 \%} \mathrm{SiC}+\mathbf{1 0 \%} \mathrm{CBA}$

Fig 9. Micrographs of the composites with different percentage of CBA and SiC.

So as to distinguish and assess the microstructure of material, it is critical to set up the test cautiously and appropriately. The attributes appearance and physical course of action of metal atoms as perceived with an optical microscope to derive conclusions about the grain size and shape, dispersion of different stages and consideration. Small scale assessment uncovers homogenous scattering of silicon carbide particles and graphite in the aluminum framework and guarantees that the material has appropriate mechanical properties. The $\mathrm{SiC}$ fortified $\mathrm{Al}-\mathrm{SiC}$ grid composite has once in a while pore, minimal structure, and great interfacial holding. Nearness of compared grains with fine intermetallic accelerates is found in the network of aluminum. 
Micrograph of the composites with different percentage of composition was shown in Fig 9.

\section{CONCLUSION}

Investigations on mechanical properties of A18011, SiC and chicken bone ash(CBA) composite are made on different specimens containing $0 \%, 2 \%, 4 \%, 6 \%, 8 \%, 10 \%$ of silicon carbide and $10 \%, 8 \%, 6 \%, 4 \%, 2 \%, 0 \%$ of chicken bone ash (CBA) respectively as reinforcements.

The result reveals that:

1. Maximum Fatigue strength is observed at percentage of $\mathrm{SiC}(2 \%)$ and chicken bone ash (10\%) added with aluminium metal (A18011) as reinforcements.

2. Greatest effect quality is acquired at most extreme rate $\mathrm{SiC}(2 \%)$ and graphite (10\%) added with aluminum metal (Al8011) as fortification.

3. Greatest Hardness is acquired at most extreme rate $\mathrm{SiC}(2 \%)$ and graphite (10\%) added with aluminum metal (Al8011) as support.

4. The microstructural contemplates uncover that the fortification particles are consistently spread in the metal network which impacts the mechanical properties impressively.

\section{REFERENCES}

[1]MahendraKV, RadhaKrishnaK 2010 "Characterization of Stir Cast $\mathrm{AlCu}$ (flyash+SiC) hybrid metal matrix composites”. Journal of Composite Materials;44 (8):989-1005.

[2] Mr.B.Suresh babu, Mr.C.Boopathi, Mr.T.Pridhar, Dr.R.Srinivasan, 2018 "Production and characterization of mechanical and microstructural behaviour of friction stir welded Al6063 composites reinforced with Gr/B4C/SiC particles", Journal of Ceramic Processing Research, ISSN 1229 - 9162, Vol.19, No.1, pp.69-74.

[3] Mr.T.Pridhar, 2018 "Mechanical properties and characterization of zirconium oxide (ZrO2) and coconut shell ash(CSA) reinforced aluminium (Al 6082) matrix hybrid composite" Journal of Alloys and Compounds, Volume 765, Pages 171-179. 
[4] Singh D, Singh H, Kumar S, Singh G.2012, An Experimental Investigation of Mechanical Behaviour of by Adding Sic and Alumina. International Journal of Emerging Technologies,; 3: $178-184$.

[5] Rasidhar L, Krishna AR, Rao S.2013, Fabrication and investigation of properties of Ilmenite (FeTiO3) based Al-Nano composite by stir casting process. International Journal of Bio-science and Bio-Technology; 5: 193-200.

[6] Mr.K.Kaviyarasan, 2018 "Extensive Review On Properties Of Metal Matrix Composites Reinforced With Fly Ash", International Journal of Mechanical Engineering and Technology (IJMET), ISSN 0976-6340, Vo19, Issue 9.

[7]SivaPrasadD,RamaKrishnaA.2011 "Production and mechanical properties of A356.2/RHA composites".International Journal of Advanced ScienceandTechnology;33:51-7.

[8]RamachandraM, RadhakrishnaK. 2005 "Synthesis-microstructure-mechanical properties wear and corrosion Behaviour of an $\mathrm{Al}-\mathrm{Si}(12 \%)-\mathrm{Fly}$ ash metal matrix composite". Journal of Materials Science; 40:5989-97.

[9] T.Nithyanandan, 2017 "Investigation of Mechanical Properties on Aluminium Based Hybrid Composites". International Journal of Innovative Research in Science, Engineering and Technology 2017 ISSN (Print): 2347 -6710 Volume 6, Special Issue 7:118-126.

[10] Mr.Haridass.R, 2018 "Determination of corrosion behaviour of al6063-sic-rha metal matrix composites", International Journal of Pure and Applied Mathematics, ISSN: 1311-8080, Volume 118 No. 20, 907-915

[11] K Kaviyarasan, T Pridhar, B Sureshbabu, C Boopathi and R Srinivasan,2018, Fabrication of Al6061-Al2O3 composite through liquid metallurgy technique IOP Conf. Series: Materials Science and Engineering, Volume 402, No 99

[12] Dr.P.Prathap, 2019, "Performance Analysis of Abrasive Water Jet Cutting Process in Carbon Fiber Epoxy Polymer Composite”, IOP Conference Series: Materials Science and 
Engineering, ISSN 1757-898,

[13] Mr.Nelson,2019, "Effect of tool material, profile and D/d ratio in friction stir welding of aluminium metal matrix composites" Materials Research Express, Volume 6, Issue 9, article id. 096590.

[14] Christy TV, Murugan N, Kumar S, 2010, "A comparative study on the microstructures and mechanical properties of Al 6063 alloy and the MMC Al 6063/TiB2/12p”. JMMCE;9:57-65. [15] Macke A, Schultz BF, Rohatgi P, 2012, "Metal matrix composites offer the automotive industry an opportunity to reduce vehicle weight, improve performance". Adv Mater Processes;170:19-23.

[16] Alaneme KK, Aluko AO, 2012, "Fracture toughness (K1C) and tensile properties of ascast and age-hardened aluminium(6063)—silicon carbide particulate composites". Sci Iran TransA;19:992-6.

[17] Mr.T.Pridhar, C.Boopathi , 2016 "The effect of particle hybridization on microstructure analysis and mechanical behavior of metal matrix composites: an experimental approach” Digest Journal of Nanomaterials and Biostructures, Vol. 11, No. 3, p. $845-852$.

[18] Mr.Nelson, 2019, "Effect of tool material, profile and D/d ratio in friction stir welding of aluminium metal matrix composites” Materials Research Express, Volume 6, Issue 9, article id. 096590.

[19] Mr.T.Pridhar ,2019 "Evaluation on properties and characterization of asbestos free palm kernel shell fibre (PKSF)/polymer composites for brake pads" Materials Research Express, Volume 6, Number 11.

[20] Mr.Justin Maria Hillary J, 2019, “A study on microstructural effect and mechanical behaviour of al6061-5\%sic-tib2 particulates reinforced hybrid metal matrix composites" journals of composite materials. 